\title{
Síndrome congênita pelo Zika Vírus (SCZ) e seus aspectos estomatológicos: uma revisão sistematizada
}

Congenital Zika Virus Syndrome (SCZ) and its stomatological aspects: a systematized review Síndrome congénito asociado el Virus Zika (SCZ) y sus aspectos estomatológicos: una revisión sistematizada

Eduarda Candida Gomes AGUIAR

Acadêmica do Curso de Graduação em Odontologia, Escola Superior de Ciências da Saúde, Universidade do Estado do Amazonas (UEA), Manaus-AM, Brasil. 69065-001 https://orcid.org/0000-0001-7836-446X

Eliane de Oliveira Aranha RIBEIRO

Mestre pela Universidade Federal do Amazonas (UFAM), Doutoranda em Educação na Universidade do Estado do Rio de Janeiro (UERJ), Professora Mestre Asssitente da Escola Superior de Ciências da Saúde, Universidade do Estado do Amazonas (UEA) Manaus-AM, Brasil. 69065-001 https://orcid.org/0000-0002-1103-4332 Catia Crivelenti de Figueiredo WALTER Professora Associada, Departamento de Educação Inclusiva e Continuada e do Programa de Pós Graduação (PROPED-UERJ), Universidade do Estado do Rio de Janeiro (UERJ), 20550-013 Rio de Janeiro-RJ, Brasil https://orcid.org/0000-0002-7033-8301

\section{Resumo}

Em 2015 houve um aumento significativo no número de crianças nascidas com microcefalia no Brasil. Vários estudos associaram este achado e outros defeitos congênitos à infeccção pelo vírus Zika, designando-se de Síndrome congênita pelo Zika vírus. Este estudo teve como objetivo pesquisar os principais aspectos estomatológicos de crianças acometidas pela síndrome congênita do Zika Vírus, por meio de uma revisão sistemática da literatura. Realizou-se uma busca dos dados nas plataformas de pesquisa PubMed, SciELO, Biblioteca Virtual em Saúde e no Google Acadêmico, de onde foram selecionados 14 artigos. Os principais achados foram: alteração na sequência e cronologia de erupção dentária; alterações de esmalte; freio lingual encurtado; grande predisposição no desenvolvimento de cáries; e doenças periodontais. A análise dos dados sugere que a inclusão do cirurgião dentista na equipe multiprofissional de cuidados a essas crianças, ainda nos primeiros meses de vida desses pacientes, é fulcral para detecção e prevenção de doenças estomatognáticas.

Descritores: Microcefalia; Infecção pelo Zika Vírus; Saúde Bucal.

\section{Abstract}

In 2015 there was a significant increase in the number of children born with microcephaly in Brazil. Several studies have associated this finding and other birth defects with infection by the Zika virus, known as Zika virus congenital syndrome. This study aimed to make a survey of the main stomatological disorders of children affected by congenital Zika Virus syndrome (SCZ) through a systematic literature review. A search was carried out on the research platforms PubMed, SciELO, Virtual Health Library and Google Scholar, where 14 articles were selected .The main findings were: alteration in the sequence and chronology of dental eruption; enamel alterations; shortened lingual brake; great predisposition in the development of caries and periodontal diseases. The analysis of the data suggests that the inclusion of the dentist in the multiprofessional team of care for these children, still in the first months of life of these patients, is central to detection and prevention of stomatognathic diseases.

Descriptors: Microcephaly; Zika Virus Infection; Oral Health.

\section{Resumen}

En 2015 hubo un aumento significativo en el número de niños nacidos con microcefalia en Brasil. Varios estudios han asociado este hallazgo y otros defectos de nacimiento con la infección por el virus Zika, conocido como síndrome congénito asociado el virus Zika. El estudio que aquí se presenta tuvo como objetivo relevar los principales aspectos estomatológicos de los niños afectados por el síndrome congénito asociado el virus Zika, através de una revisión sistemática de la literatura. Para ello, se realizó una búsqueda de los datos en las plataformas de investigación PubMed, SciELO, Biblioteca Virtual em Saúde y Google Scholar, de las cuales se seleccionaron 14 artículos. Los principales hallazgos fueron: alteración en la secuencia y cronología de la erupción dentaria; cambios de esmalte; freno lingual acortado; gran predisposición en el desarrollo de caries; y enfermedades periodontales. El análisis de los datos sugiere que la inclusión del cirujano dentista en el equipo de atención multidisciplinar de estos niños, aún que en los primeros meses de vida de estos pacientes, es fundamental para la prevención de las enfermedades estomatognáticas.

Descriptores: Microcefalia; Infección por el Virus Zika; Salud Bucal

INTRODUÇÃO

A microcefalia é uma má-formação congênita que se caracteriza pelo subdesenvolvimento do cérebro, com fontonelas (espaços abertos entre os ossos da calota craniana) fechados prematuramente; possui uma etiologia complexa e multifatorial, observável clinicamente um perímetro craniano menor que o normal, quando comparado ao de uma criança de mesma idade e sexo. Pode ainda apresentar outras características, tais como estrutura cerebral alterada e problemas de desenvolvimento neurológico e pode estar presente nas infecções por Zika Vírus transplacentária ${ }^{1}$.

O vírus Zika (ZIKV) é um arbovírus pertencente ao gênero Flavivirus (família
Flaviviridae), encontrado pela primeira vez no sangue de macacos em Uganda, em $1947^{2}$. No ano seguinte, foi isolado em mosquitos Aedes africanus e identificado, em 1952, em humanos nas regiões de Uganda, Tanzânia e Nigéria ${ }^{3}$. Seus principais agentes transmissores são os mosquitos Aedes aegypit e Aedes albopictus. Porém, estudos encontraram ZIKV em fluidos corporais, como saliva, sangue, sêmen e urina, sendo estes também uma forma de transmissão do vírus - mas não apenas estas ${ }^{4-8}$.

Durante um surto na Polinésia Francesa, foram coletadas amostras de soro de duas mães e seus bebês, com apenas quatro dias de nascidos, e obtiveram a infecção pelo Zika Vírus confirmada pelo exame RPC. Com isso os 
pesquisadores concluíram que o Vírus Zika pode ser disseminado por transmissão transplacentária ou durante o parto ${ }^{9}$.

O primeiro relato de transmissão no Brasil se deu em maio de 2015, quando houve também um aumento significativo no número de crianças nascidas com microcefalia, só no estado de Pernambuco foram notificados mais de 600 casos até novembro do mesmo ano ${ }^{10}$.

O diagnóstico da microcefalia pode ser realizado durante o pré-natal, através de exame de ultrassonografia, ou após as primeiras 24 horas de vida. O recém-nascido que tem suspeita de microcefalia deve ser submetido a uma série de exames, tanto físicos quanto de imagem. A primeira opção é a ultrassonografia transfontanela. $O$ diagnóstico é obtido quando o perímetro cefálico é inferior a dois desviospadrão, se comparado com o de um bebê de mesma idade gestacional e gênero ${ }^{11}$.

Apesar de não haver tratamento para microcefalia, o Sistema Único de Saúde (SUS) oferece acompanhamento e auxílio no desenvolvimento para as crianças com essa deficiência. Até os três anos, elas devem ser incluídas ao Programa de Estimulação Precoce, que se encontram nos Centro Especializados de Reabilitação (CER) como também nos Núcleos de Apoio à Saúde da Família (NASF) ${ }^{11}$.

Pessoas com microcefalia são consideradas pacientes com necessidades especiais (PNE) ou pessoas com deficiência $(\mathrm{PcD})$, por apresentarem uma condição que os torna necessitados de cuidados médicos e odontológicos diferenciados, com profissionais capacitados para atender à sua condição ${ }^{12}$.

Essas crianças apresentam comprometimento grave no desenvolvimento neuropsicomotor, além de poderem ser acometidas por quadros convulsivos, alterações visuais, auditivas e articulares. Quanto às alterações físicas, podem apresentar tonos musculares alterados, transtorno no aparelho locomotor, com pés tortos, luxação de quadril, artrogripose nos quadris, joelhos tornozelos e punhos $^{13}$.

Indivíduos com doenças neurológicas geralmente não respondem a estímulos e a comandos, o que dificulta o controle do biofilme dental $e$ as torna total ou parcialmente dependentes de cuidadores que mantenham a cavidade bucal e o corpo higienizados. Diante disso, é papel dos cirurgiões-dentistas fornecer orientações de higiene bucal e hábitos alimentares aos pais durante os primeiros meses de vida dessas pessoas. É importante também que o profissional esclareça sobre a importância das consultas regulares, visando sempre melhorias para a qualidade de vida desses sujeitos e de suas famílias ${ }^{14}$.

Estudos apontam que as crianças com microcefalia causada pelo ZIKV podem apresentar mais predisposição para doenças bucais, como a cárie dentária, doença periodontal, má oclusão, micrognatia, erupção dentária retardada, disfagia, bruxismo, traumas dentários, formação anormal do palato, hipotonia, mandíbula retrógada e amplo espaço entre os dentes ${ }^{14,15}$.

O conhecimento das alterações bucais é relevante para a realização do atendimento odontológico e para a atenção em saúde bucal desses pacientes. Portanto o objetivo desse estudo é fazer um levantamento dos principais achados bucais de crianças acometidas pela síndrome congênita pelo Zika Vírus (SCZ), por meio de revisão sistemática de literatura.

MATERIAL E MÉTODO

Este estudo, de caráter descritivo, consiste em uma revisão sistemática da literatura sobre os achados bucais em crianças com SCZ. A estratégia empregada foi a busca de artigos relacionados à síndrome, recorrendose às bases de dados Pubmed, Scielo, Biblioteca Virtual em Saúde (BVS) e o Google Acadêmico, com os descritores "achados bucais", "odontologia", "SCZ", em português, inglês e espanhol.

Inicialmente, foi realizada a busca nas plataformas, com base no título do artigo e em seu resumo, tendo como critérios de inclusão: período das publicações - de janeiro de 2016 a julho de 2020; população estudada - crianças com SCZ; relação com a odontologia - estudo sobre os achados bucais; idioma de publicação - português, inglês e espanhol. Não foram feitas restrições a respeito do tamanho amostral. Foram excluídos os artigos que, além de não obedeceram aos critérios de inclusão supracitados, eram repetidos ou anteriores a 2016. Posteriormente, procedeu-se à leitura completa de cada artigo, avaliando a metodologia (se era bem descrita) e a amostragem de resultados (se foram bem realizados e descritos).

RESULTADOS

A estratégia de busca resultou em 124 artigos que, após aplicados os critérios de inclusão/exclusão, obteve-se um total de 14 artigos que compõe esta revisão. Foram encontrados 8 artigos na base de dados Google Acadêmico, 4 na Pubmed, 1 na BVS e 1 na SciELO. Com relação ao idioma 6 artigos foram publicados em português, 8 em inglês e não foram encontrados artigos referente ao tema em espanhol. No que se refere aos tipos de 
desenhos, 4 artigos são voltados para a revisão de literatura, 3 versam sobre estudos observacionais, 2 longitudinais, 4 transversais e apenas 1 trata de caso clínico.

Os principais resultados encontrados nessa revisão dizem respeito a: problemas na cronologia e sequência na erupção dos dentes decíduos, problemas de esmalte e alteração no tônus muscular.

DISCUSSÃO

- Cronologia e sequência de erupção dentária

Em um estudo com 74 crianças, D'Agostino et al. $^{16}$ notaram que a primeira erupção ocorria entre o $4^{\circ}$ e $17^{\circ}$ mês, sendo que os meses que mais obtiveram registros foram no $8^{\circ}, 9^{\circ}$ e $11^{\circ}$ mês. Já a pesquisa de Carvalho et al. ${ }^{15}$ envolveu 30 crianças e relatou a idade média da primeira erupção aos 10,8 meses, ressaltou ainda que 0 atraso da primeira erupção está associado à micrognatia. Ambos, portanto, notaram desordem na cronologia e na sequência eruptiva durante seus estudos, e em alguns casos observaram o irrompimento dos primeiros molares antes da completa erupção de todos os incisivos inferiores ${ }^{15,16}$.

As crianças com SCZ, quando comparadas com crianças sem a síndrome ${ }^{15}$, apresentaram seu primeiro aparecimento dentário significativamente mais tarde. Tais resultados corroboram os de Siqueira et al. ${ }^{17}$, os quais, a partir de análises, verificaram que esses pacientes são mais propensos a exibir mudanças na sequência e erupção dentária que crianças normais. Essas alterações podem estar associadas a má postura lingual ${ }^{15}$.

Nas análises radiográficas de Silva et al. $^{18}$ foi verificado que todos os indivíduos apresentavam botões dentais dos dentes decíduos e coroas de molares permanentes, porém três deles apresentavam dentes faltantes. Esse dados são compatíveis com o trabalho de Carvalho et al ${ }^{15}$.

Marinho et al. ${ }^{19}$, durante a revisão de literatura, relataram um caso clínico de paciente, não encontrando alterações de cronologia nem de sequência eruptiva. Tais resultados corroboram com os de Oliveira et al. ${ }^{20}$.

Cavalcanti et al. ${ }^{21}$ em seu estudo notaram distúrbios eruptivos. Além disso, os sinais e sintomas mais relatados pelas mães foram: aumento da salivação, irritabilidade e prurido gengival. Contudo, essas características são comuns durante o período de erupção dentária e não correspondem, portanto, a um desvio do padrão de normalidade. A maioria das genitoras fez uso de medicação para alívios dos sintomas e nenhuma delas fez uso de mordedores orais, pois os filhos apresentavam desordem muscular ${ }^{21}$. Ressalta-se que o uso de medicamentos para alívio dos sintomas deve ser evitado, principalmente os de uso tópico, pois a maioria contém anestésico em sua composição e pode ser ingerido pelas crianças.

- Outros achados bucais

Siqueira et al. ${ }^{17}$, Silva et al. ${ }^{18}$, Marinho et al. ${ }^{19}$, Sousa et al. ${ }^{22}$, Rodrigues et al. ${ }^{23}$, Amorim et al. $^{24}$ em sua pesquisa descreveram alterações no esmalte dentário, como a hipoplasia e a opacidade, porém Sousa et al. ${ }^{22} \mathrm{e}$ Amorim et al. ${ }^{24}$ não encontraram relevância estatística na associação da SCZ com os defeitos de esmalte.

Alterações em tecido moles, como úlceras aftosas, edema de palato mole e cistos eruptivos, foram encontrados por Amorim et al. ${ }^{24}$ e Silva et al. ${ }^{18}$. Todavia, Cota et al. ${ }^{25}$, ainda que não tenham encontrado lesões nos tecidos moles, observaram que os pacientes apresentavam hiperplasia gengival. Moro et al. ${ }^{26}$ correlacionaram esse aumento gengival aos medicamentos anticonvulsivantes que geralmente são administrados a essas crianças.

As crianças com a síndrome apresentam grande predisposição no desenvolvimento de cáries e doenças periodontais ${ }^{19,20,24-27}$, pois algumas fazem uso de medicamentos ricos em sacarose ${ }^{23,26}$. Menezes et al. ${ }^{27}$ associaram essa predisposição ao atraso nas habilidades motoras, que os impede da realização dos cuidados adequados, ficando dependentes de um cuidador para a realização das tarefas, o que pode ser dificultado principalmente porque em algumas crianças apresentam boca pequena $^{23,27}$. Devido à hipoplasia de esmalte esses indivíduos apresentam maior rapidez na cavitação das lesões cariosa de manchas brancas ${ }^{19}$.

Marinho et al. ${ }^{19}$ e Fonteneles et al. ${ }^{28}$ encontraram frênulo lingual em todos os pacientes examinados. Porém, alguns se apresentavam submucoso e em uma posição mais posterior, causando um má posicionamento da língua, o que corrobora com o atraso na erupção dentária descrito por Carvalho et al. ${ }^{15}$

\section{- Atendimento odontológico}

Ainda não existe um protocolo préestabelecido sobre as condutas que o cirurgião dentista deve adotar durante $\mathrm{o}$ atendimento a uma criança microcefálica ${ }^{23}$. Apesar disso, recomenda-se a realização de uma anamnese detalhada $^{23,27}$ e que se orientem os pais ou cuidadores sobre os cuidados da cavidade oral, hábitos deletérios e alimentação ${ }^{23,26,27}$. Com relação às consultas, estas devem ser realizadas no menor tempo possível ${ }^{23,27}$, com o 
paciente posicionado levemente inclinado para evitar a deglutição de algo indesejado ${ }^{23,26}$.

Por se tratar de pacientes especiais, os microcefálicos necessitam de atendimento especializado e que 0 dentista possua conhecimentos sobre a patologia, para garantir melhores condições orais ${ }^{23,24}$. É importante ressaltar que as medidas preventivas são de extrema importância, pois reduzem o risco de instalação de doenças ${ }^{23}$.

CONCLUSÃO

Com esta revisão pudemos observar que as manifestações orais mais predisponentes nessas crianças são: desordens na sequência e cronologia de erupção dentária; alterações de esmalte; freio lingual encurtado; grande predisposição no desenvolvimento de cáries; e doença periodontal.

Diante disso, considera-se que a inclusão do cirurgião dentista na equipe multiprofissional de cuidados a essas crianças (ainda nos primeiros meses de vida) é de grande importância na prevenção de doenças, preservação de estruturas dentais e na rápida detecção de problemas orais inerentes a esses indivíduos. É importante ainda a orientação aos cuidadores sobre a higiene oral, visto que eles serão os principais responsáveis por ela.

\section{REFERÊNCIAS}

1. Leite CN, Varellis MLZ. Microcefalia e a odontologia brasileira. J Health NPEPS. 2016; 1(2):297-304.

2. Cugola FR, Fernandes IR, Russo FB. The Brazilian Zika virus strain causes birth defects in experimental models. Nature. 2016; 534(7606):267-71.

3. Wong SS, Poon RW, Wong SC. Zika virus infection-the next wave after dengue? J Formos Med Assoc. 2016;115(4):226-42.

4. Petersen E, Wilson ME, Touch S. Rapid Spread of Zika Virus in The Americas--Implications for Public Health Preparedness for Mass Gatherings at the 2016 Brazil Olympic Games. Int J Infect Dis. 2016;44:11-15.

5. Musso D, Nhan T, Robin E. Potential for Zika virus transmission through blood transfusion demonstrated during an outbreak in French Polynesia, November 2013 to February 2014. Euro Surveill. 2014;19(14):15-9.

6. Musso D, Roche C, Robin E, Nhan T, Teissier A, Cao-Lormeau VM. Potential sexual transmission of Zika virus. Emerging infectious diseases. 2015;21(2):359-61.

7. Gourinat AC, O'Connor O, Calvez E, Goarant C, Dupont-Rouzeyrol M. Detection of Zika virus in urine. Emerg Infect Dis. 2015;21(1):84-6.

8. Musso D, Roche C, Nhan TX, Robin E, Teissier A, Cao-Lormeau VM. Detection of Zika virus in saliva. J Clin Virol. 2015;68:53-5.
9. Kindhauser MK, Allen T, Frank V, Santhana RS, Dye C. Zika: the origin and spread of a mosquito-borne vírus. Bull World Health Organ 2016;94(9):675-86

10. Melo ASO, Malinger G, Ximenes R, Szejnfeld PO, Sampaio SA, Bispo de Filippis M. Zika virus intrauterine infection causes fetal brain abnormality and microcephaly: tip of the iceberg? Ultrasound Obstet Gynecol.2016; 4(7): 6-7.

11. Ministério da Saúde (BR). Secretaria de Vigilância em Saúde. Síndrome congênita associada à infecção pelo vírus Zika: situação epidemiológica, ações desenvolvidas e desafios, 2015 a 2019. Bol Epidemiol. 2019.

12. Oliveira ALBMD, Giro EMA. Importância da abordagem precoce no tratamento odontológico de pacientes portadores de necessidades especiais. Odonto. 2011;19(38): 45-51.

13. Flor CJDRV, Guerreiro CF, Dos Anjos JLM. Desenvolvimento neuropsicomotor em crianças com microcefalia associado ao Zika Vírus. Pesqui Fisioter. 2017;7(3):313-18.

14. Siqueira RMP, Marinho ABAS, Santos MTBR, Cabral GMP. Dental care for children with Congenital Zika Syndrome. RGO, Rev Gaúch Odontol. 2020;68:e20200014.

15. Carvalho IF, Alencar PNB, Carvalho de Andrade MD, Silva PGDB, Carvalho EDF, Araújo LS et al. Clinical and x-ray oral evaluation in patients with congenital Zika Virus. J Appl Oral Sci. 2019;27.

16. D'Agostino ÉS, Chagas JRLP, Cangussu MCT, Vianna MIP. Chronology and sequence of deciduous teeth eruption in children with microcephaly associated to the Zika virus. Spec Care Dent. 2019;40(1):3-9

17. Siqueira RMP, Santos MTBR, Cabral GMP. Alterations in the primary teeth of children with microcephaly in Northeast Brazil: a comparative study. Int J Paediatr Dent. 2018;28(5):523-32.

18. da Silva MCPM, de Andrade Arnaud M, Lyra MCA, de Alencar AV, Filho, Rocha MÂW, Ramos RCF, et al. Dental development in chilfren born to Zikv-infected mothers: a casebased study. Arch Oral Biol. 2020;110:104598.

19. Marinho JVM, Mousinho KC, Panjwani CMBRG, Ferreira SMS, Vanderlei AD. Aspectos clínicos da cavidade oral de pacientes com a síndrome congênita do zika: revisão da literatura. Diversitas J. 2020;5(1): 57-65.

20. Kohashi BSDO, Ribeiro EDOA, Soares KS, Prestes GBDR. Abordagem preventiva e educativa em paciente odontológico com microcefalia associada ao Zika vírus: relato de caso. Arch Health Invest. 2019;8(1):33-8.

21. Cavalcanti AFC, Aguiar YPC, de Oliveira MAS, de Freitas LJIB, Cavalcanti AL, Cavalcanti 
SDÁLB. Teething symptoms in children with congenital Zika syndrome: A 2-year follow-up. Int J Paediatr Dent. 2018;29(1):74-8.

22. Sousa MM. O desenvolvimento de defeitos na estrutura de dentes decíduos em crianças portadoras da síndrome congênita do Zika vírus [monografia]. Rio Grande do Norte: UFRN; 2017.

23. Rodrigues LAC, Mohn-Neto CR. Microcefalia congênita pelo Zika Vírus: cuidados odontológicos. Sci Investig Dent. 2019;24(1): 79-87.

24. Amorim JGDP. Condição de saúde oral em crianças com microcefalia por infecção pelo Zika vírus: estudo transversal observacional [dissertação]. Rio Grande do Norte: UFRN; 2018.

25. Cota ALS, Lopes MGM, Pio IM, de Oliveira MJ, Rodrigues DF, Panjwan CMBRG. Oral findings in children with congenital Zika Syndrome: a case serie. Saúde e Pesquisa. 2020;13(1):133142.

26. Moro JS, Marega T, ROMAGNOLO FU. Microcephaly caused by the Zika virus: dental care. RGO Rev Gauch Odontol. 2019;67.

27. de Menezes PCB, de Oliveira PY, Girão DC, de Albuquerque VA, de Araujo ML, Cunha KAC, et al. Síndrome congênita do Zika vírus - um novo desafio ao odontopediatra: uma revisão bibliográfica. REAS. 2020;12(3).

28. Fonteles CSR, Ribeiro EM, Santos MSA, Leite RFP, Assunção GS, Monteiro AJ, et al. Lingual frenulum phenotypes in Brazilian infants with congenital Zika syndrome. Cleft Palate Craniofac J. 2018;55(10):1391-98.

\section{CONFLITO DE INTERESSES}

Os autores declaram não haver conflitos de interesse

AUTOR PARA CORRESPONDÊNCIA

\section{Eduarda Candida Gomes Aguiar}

Rua: Rio Tique, № 42, São José

69086-350 Manaus - AM, Brasil

ecga.odo16@uea.edu.br

Submetido em 18/12/2020

Aceito em 16/07/2021 